\title{
Colloidal Solutions with Silicon Nanocrystals: Structural and Optical Properties
}

\author{
Abel Garzón Román, José Alberto Luna López, \\ Álvaro David Hernández de la Luz, \\ Estela Gómez Barojas, Alfredo Benítez Lara, \\ Diana Elizabeth Vázquez Valerdi and \\ Miguel Ángel Domínguez Jimenez
}

Additional information is available at the end of the chapter

http://dx.doi.org/10.5772/intechopen.74429

\begin{abstract}
In this work, colloidal solutions with silicon nanoparticles using different solvents were synthetized. Structural, morphological and optical characterizations were realized, and these were studied. X-ray diffraction (XRD) was used to measure the diffractograms of the colloidal solutions, which are composed of silicon nanocrystals (Si-ncs), with an average size of approximately $3 \mathrm{~nm}$, and a preferential crystalline orientation (311). Atomic force microscopy (AFM) images show that the morphology of silicon nanoparticles (Si-nps) is agglomerated in a big amount, which is corroborated by means of the roughness. On the other hand, high resolution transmission electronic microscopy (HRTEM) images show on average size of the Si-nc ranging from 1.5 to $10 \mathrm{~nm}$, which depends on the solvent used. Also, different preferential crystalline orientations of the Si-nc such as (311), (220) and (111) were obtained. A correlation between the optical and structural properties was realized in colloidal solutions with silicon nanoparticles and different solvents.
\end{abstract}

Keywords: silicon nanocrystals, colloidal solutions, porous silicon, XRD, AFM, HRTEM

\section{Introduction}

In the last years, the synthesis of the silicon nanostructures has been developed in grand manner, due to both by their interesting quantum effects that these structures present and also by their interesting optical and unique electrical properties. A fundamental result that has been found in the silicon nanocrystals (Si-ncs) is that they make a contribution to the shifting in the 
prohibited energy band. Thus, we observed in the measurements that the energy band gap increases when decreasing the Si-nc size [1-3]. Other interesting result is related to the emission efficiency of light in the visible range, which is linked to the energy band gap of the Si-nc, which in turn depends strongly on the size of the Si-ncs, and when they have lesser size than the Bohr exciton radius in the silicon, the spatial confining of the carriers in the nanocrystal is greater, which gives rise to a strong overlap of the wave functions in the k-space in both electrons and holes. Therefore, the nanocrystals can absorb and emit light with different energies by controlling only their size [4]. Silicon nanocrystals have been widely exploited in electronics and other areas, due to their low toxicity, and they exhibit the ability to be doped in order to become either an n-type or p-type material [5]; this fact allows generating new technologies such as sensors [6-8], biosensors [9-12], magnetic materials [13], photodiodes [14], Bragg reflectors [15], photonic applications [16-21], nonvolatile storage devices [22-24], solar cells of third generation [25-29] as well as tandem solar cells [30-35], among other devices [35, 36].

Actually, it exists a big interest in the topic of photovoltaic energy, due to Queisser-Shockley theory limit, in one standard solar cell of Si where there is a loss of efficiency due to the phonon scattering phenomenon that is produced by the hot electrons. To eliminate such undesirable effects, it has been proposed two alternatives for improving the efficiency of such $\mathrm{Si}$ cell. The first one consists of making heterostructures with materials of different energy band gaps; in each layer forming the heterostructure, the energy will be absorbed and transformed into electric energy. The second one is based on the down conversion process that consists of depositing one layer on the solar cell and using the photoluminescent effect to reduce the energy of incident photons. These photons make a more efficient conversion of the solar energy into electric energy. These two ways proposed require a careful control of the size of the nanocrystals [4].

Today, there are a lot of methods for obtaining silicon nanocrystals, namely Stober, pulsed laser, controlled precipitation, emulsions, oxidation, silane combustion, gas evaporation, cosputtering and thermic degradation [37-48], chemical vapor deposition (CVD) [49, 50], low pressure chemical vapor deposition (LPCVD) [51], ionic implantation [52,53] and other ones. Unfortunately, such methods are very expensive. As an alternative, a method consisting of using colloidal solutions for obtaining Si-ncs may be used. We have reported somewhere previously how to obtain these colloidal solutions [54]. In this chapter, we report the observed structural and morphological properties of silicon nanocrystals in different organic solvents as colloidal solutions with Si-ncs, and we quantify the exact size of these nanocrystals.

\section{Experimental method}

The first step to obtain the silicon nanocrystals consisted on obtaining the porous silicon (PSi). To synthetize the PSi, we used the electrochemical etching process for which was used hydrofluoric acid (HF) with different electrical current densities. The obtained PSi samples were subjected to a scrapped-off process, and after this, a grinding process was carried out in an agate mortar. 
After the latter process a fine powder was obtained, it was mixed with organic solvents (acetone, methanol and ethanol) and then a process of decanting over the larger particles found in the solution was done. Finally, almost transparent solutions were obtained as observed at a glance, but when they were exposed under UV radiation, they showed an efficient photoluminescence lying between green and blue colors. The obtaining of nanocrystals by means of colloidal solutions was previously reported by the authors [54]. Therein, the process used to obtain the nanocrystals is explained in detail.

The structural properties of the silicon nanocrystals were determined by the high resolution transmission electronic microscopy (HRTEM) technique with a JEOL-2010 HRTEM (Jeol, Tokyo, Japan) system with a potential of $200 \mathrm{kV}$. The X-ray diffractograms were obtained with Discover Bruker D8 equipment operated at $40 \mathrm{kV}$ and at $40 \mathrm{~mA}$ using a CuKa radiation $\left(1.5406^{\circ}\right)$, with a Lynxeye detector and a $0.2 \mathrm{~mm}$ divergence grid as primary optics and a grid of $3 \mathrm{~mm}$ anti-dispersion as secondary optics. The morphological properties were studied by atomic force microscopy (AFM) with a JEOL JSPM-5200 team.

\section{Results and discussion}

\subsection{X-ray diffraction (XRD)}

To obtain the diffractograms of the colloidal solutions, we deposited a colloidal solution on silicon substrates with crystalline orientation (100), so that they functioned as support to the Si-ncs. The diffraction pattern peaks obtained in the diffractogram are localized near those that have been reported in Ref. [55]; the case of crystallographic planes is also similar [56-59]. This result indicates clearly that there are silicon nanocrystals in our silicon substrate. On the other hand, the XRD data show that Si-ncs have a preferential crystalline orientation (311). However, in some samples (M_09 and M_15), additional peaks were found around $2 \theta=28.52^{\circ}(111)$, $47.31^{\circ}(220)$, and this may be due to the existence of some type of metastable state of the silicon nanocrystals on the silicon substrate as indicated in Figure 1. By using the average width of the diffraction peak (FWHM), the average size of the nanocrystals could be calculated by applying the Scherrer equation [60,61]. Table 1 shows a comparison between the diffracted peaks of JCPDS card 27-1402, with respect to the diffracted peaks belonging to our samples obtained.

Some papers report that these diffraction peaks are originated by the core/shell structures, where such structures are formed from the combination of silicon nanocrystals coated by an oxide layer [57], due to the etching process in which HF was utilized to obtain the PSi and the subsequent atmospheric exposure.

It was observed that the average size of the nanocrystals varied from 2.88 to $3.67 \mathrm{~nm}$ according to the data reported in Table 1. In the work that was reported in Ref. [54], it is possible to observe that the nanocrystals have the tendency to orientate themselves in the crystallographic plane (111), but with nanocrystals having a larger size. However, when the nanocrystals were directly measured, it was found that their preferential orientation changed to (311) with smaller sizes. This can be attributed to the fact that the sizes of larger crystals 

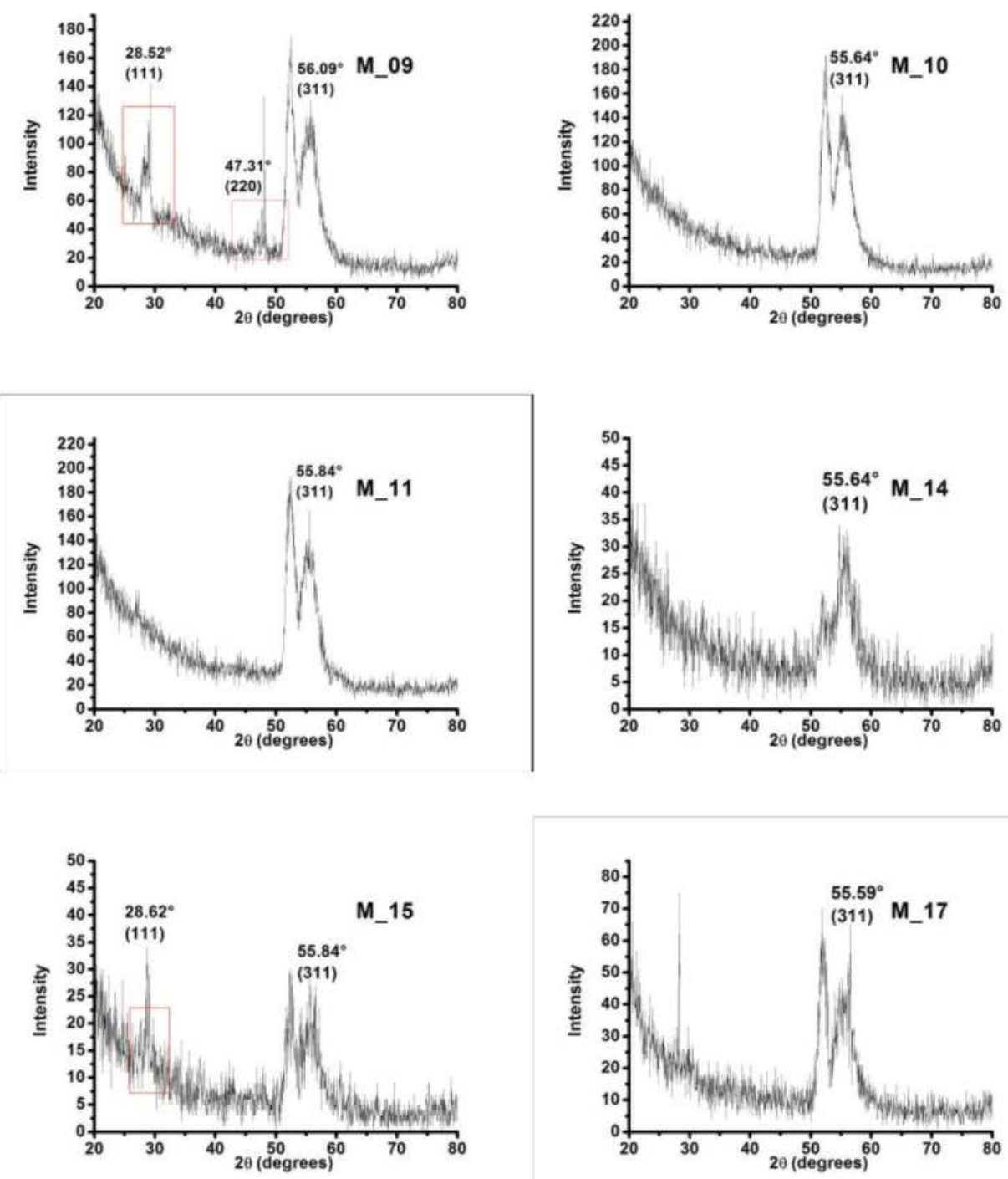

Figure 1. XRD diffractograms of the colloidal solutions obtained.

are due to the agglomerations of small crystals, thus producing a preferential orientation as a consequence of this agglomeration. When we carry out the measurement of the smallest crystal dimensions, in a certain way we measure the crystal dimensions individually; therefore, we can say that we are measuring the true natural orientation of the nanocrystals which is possibly because of the way of preparation of the colloidal solution samples, contrary to other works where they have different orientation tendencies of the crystals such as (111) 


\begin{tabular}{|c|c|c|c|c|c|c|c|c|c|c|c|c|}
\hline \multirow{2}{*}{$\begin{array}{l}\text { Ref. [57] } \\
\text { Peak } \\
\text { position } \\
\text { (PP) }\end{array}$} & \multicolumn{2}{|c|}{ Sample M_09 } & \multicolumn{2}{|c|}{ Sample M_10 } & \multicolumn{2}{|c|}{ Sample M_11 } & \multicolumn{2}{|c|}{ Sample M_14 } & \multicolumn{2}{|c|}{ Sample M_15 } & \multicolumn{2}{|c|}{ Sample M_19 } \\
\hline & PP & $\begin{array}{l}\text { Size } \\
(\mathrm{nm})\end{array}$ & PP & $\begin{array}{l}\text { Size } \\
(\mathrm{nm})\end{array}$ & PP & $\begin{array}{l}\text { Size } \\
(\mathrm{nm})\end{array}$ & PP & $\begin{array}{l}\text { Size } \\
(\mathrm{nm})\end{array}$ & PP & $\begin{array}{l}\text { Size } \\
(\mathrm{nm})\end{array}$ & PP & $\begin{array}{l}\text { Size } \\
(\mathrm{nm})\end{array}$ \\
\hline 28.44 & 28.52 & 4.88 & N/A & N/A & N/A & N/A & N/A & N/A & 28.62 & 2.19 & N/A & N/A \\
\hline 47.30 & 47.31 & 4.19 & N/A & N/A & N/A & N/A & N/A & N/A & N/A & N/A & N/A & N/A \\
\hline 56.12 & 56.09 & 2.88 & 55.64 & 3.18 & 55.84 & 3.24 & 55.74 & 3.06 & 55.84 & 3.67 & 55.59 & 3.62 \\
\hline
\end{tabular}

Table 1. XRD peaks position and nanocrystal size obtained from the samples.

[60] or an orientation (220) [4]. An important feature which is noteworthy to emphasize is the intensity of the diffraction peaks; such intensity is attributed to the thickness formed by the silicon nanocrystals on the substrate [4]. Therefore, we suggest that the intensity of the peaks depends strongly on the amount of nanocrystals found.

\subsection{AFM characterization}

The characterization by atomic force microscopy was realized in all colloidal solutions with Si-ncs, in order both to know the roughness of the samples and to demonstrate the existence of silicon nanocrystals by using another characterization technique. The colloidal solution samples were deposited on p-type silicon substrates with orientation (100). The results were the following: all the samples presented particles with spherical shapes welldefined and sometimes irregular shapes, similar to particle agglomerations. The sample M_09 exhibited a set of particles forming several geometries, as can be seen in the XY scale of the image. In this scale, the dimensions of such particles lie in the micron order, but in the $\mathrm{Z}$ scale, we find that they have a maximum of $186 \mathrm{~nm}$. Therefore, we can say that there are agglomerates of crystals in the $X Y$ plane with micrometric dimensions which have along the $\mathrm{Z}$ direction nanometric dimensions. The largest particles have a height of $186 \mathrm{~nm}$ and it decreases until finding particles with a height approximately of $18 \mathrm{~nm}$. The 3D image shows the roughness surface of the substrate due to the layer of the colloidal solution that was deposited as shown in Figure 2.

By taking a specific area of the image, it was possible to locate an area where particles with heights approximately from 1 to $2.3 \mathrm{~nm}$ were found. On the other hand, nanometric particles could also be found in the $X-Y$ plane. Besides, there are agglomerated particles whose size is around $100 \mathrm{~nm}$ in the $\mathrm{XY}$ plane with a height of approximately $30 \mathrm{~nm}$. This dispersion in size that occurs between the images is due to the sections that are reviewed in the sample as is shown in Figures 2 and 3. However, with this information obtained from these images, we can determine and verify that we really have particles of nanometric size.

Similar situation happened for samples M_10, M_11, M_14, M_15 and M_17 because they also had particles with different geometric shapes which in general exhibit a tendency to be spherical. At first glance, it was observed in a large area comprising micron-sized dimensions, but 

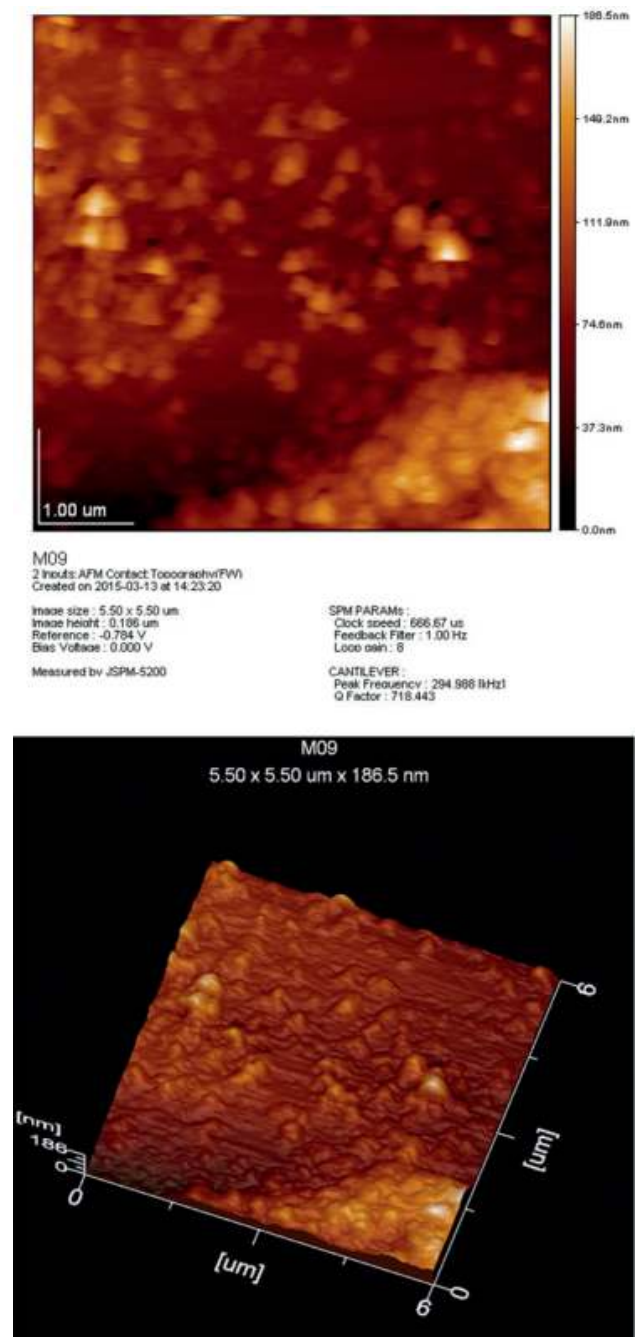

Figure 2. AFM image and 3D image obtained from the sample M_09.

it was also possible to see agglomerated particles with dimensions in the order of hundreds of nanometers, with similar heights. This occurred for some areas studied as shown in Figure 4.

On the other hand, by observing specific areas of the samples, particles of smaller sizes could be detected. We could also reduce the scanning area, and we could find a quantity of nanometric particles in the $\mathrm{X}-\mathrm{Y}-\mathrm{Z}$ space with a size of approximately $1.8 \mathrm{~nm}$. These images clearly demonstrate the existence of silicon nanoparticles.

Figure 5 shows the contrast between individual particles that can be found and agglomerates that are produced by the junction of individual particles. The origin of the agglomeration process is not yet clear; we assume that this mechanism may be due to several factors, such as the preparation of the samples, the deposition of the colloids on the substrate or the density of suspended particles in the solvents. 


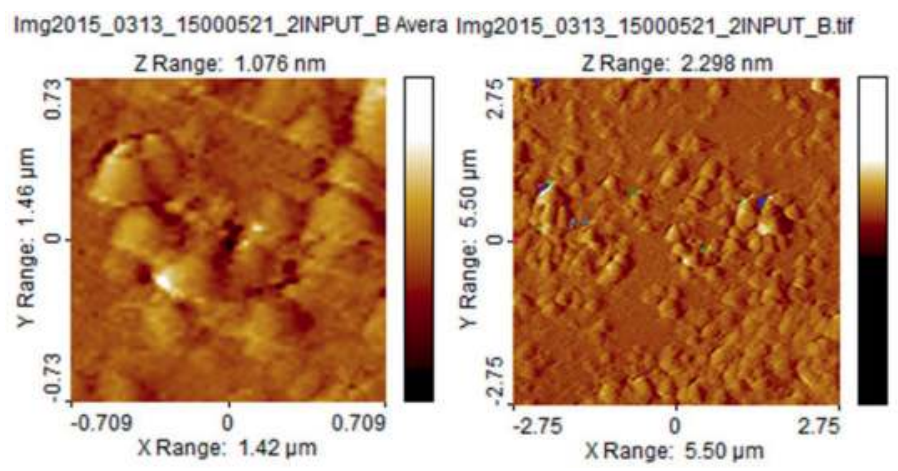

Figure 3. The X-Y plane of the sample M_09 with agglomerations of nanometric size.

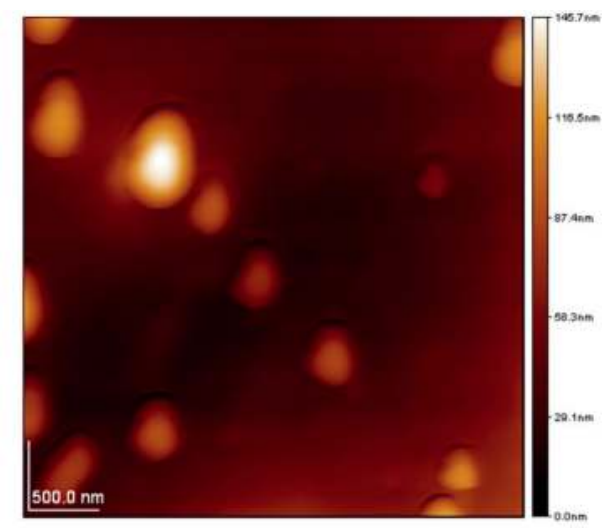

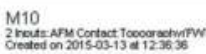
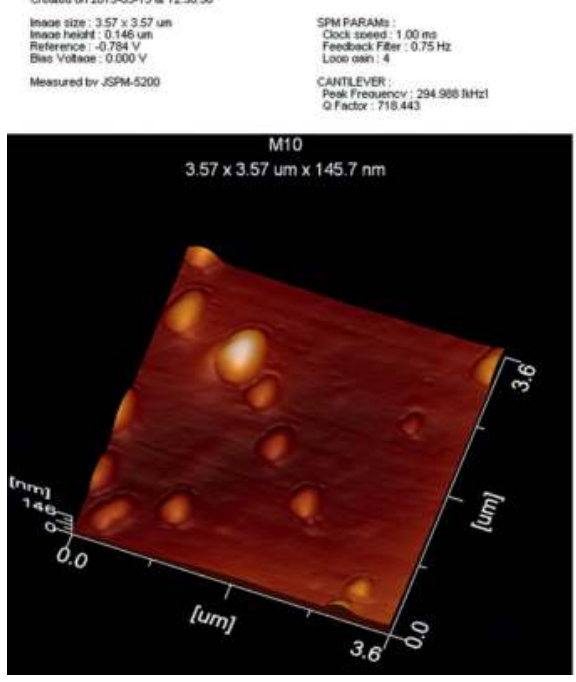

Figure 4. The X-Y plane and 3D image of the colloidal solution sample with Si-ncs. 
Img2015_0313_12361114_2INPUT_B.tif
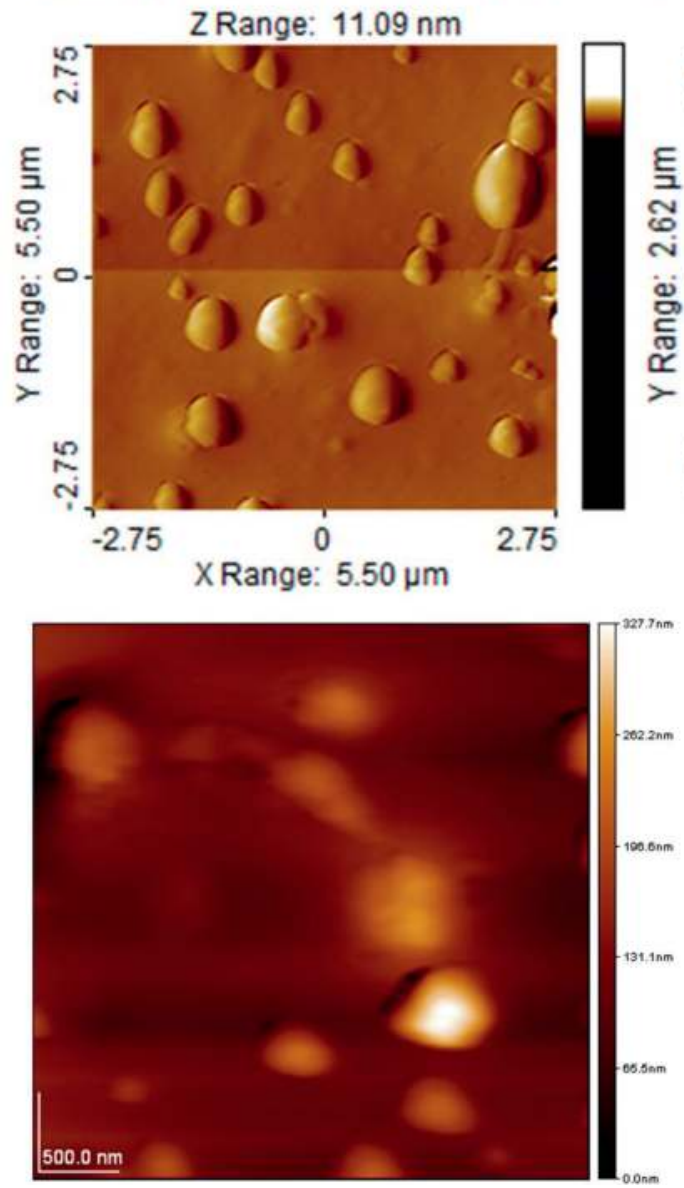

Img2015_0314_12401123_2INPUT_B
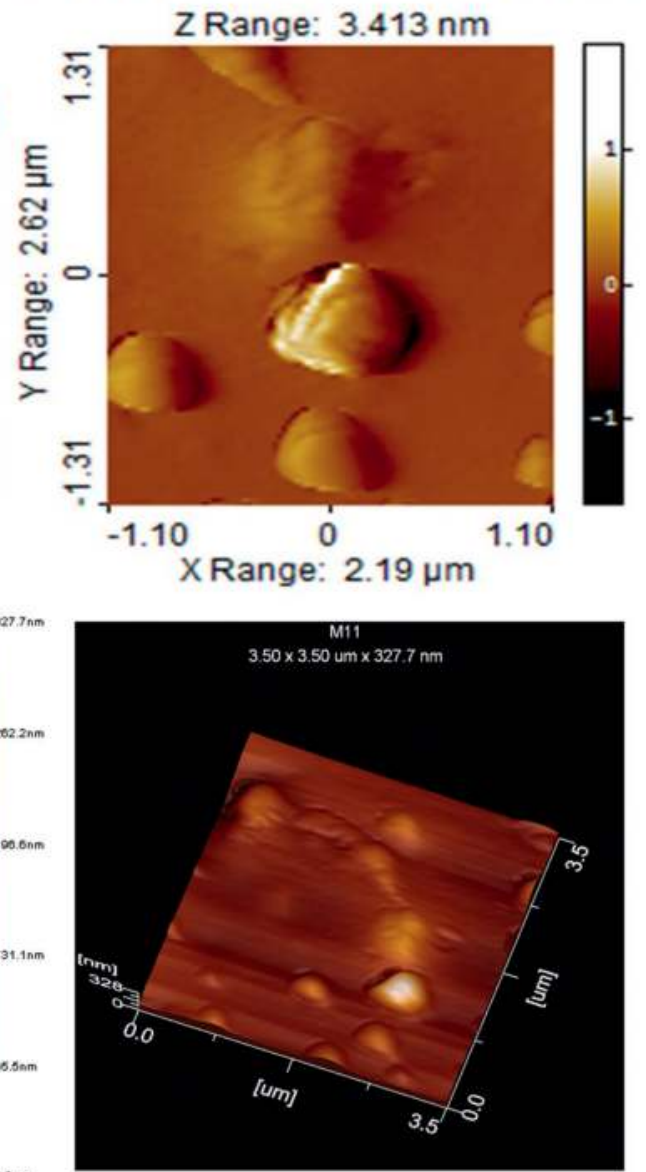

Figure 5. Junction of individual particles generating an agglomeration process.

It is clear that we can corroborate the X-ray diffraction data with these results because in XRD there are average crystal sizes between 1.5 and $3 \mathrm{~nm}$, and it is clear that we are obtaining similar crystal sizes by means of this characterization technique.

For sample M_14, a remarkable fact happened, it consisted of agglomerations of particles, but in a particle image there were longitudinal agglomerations, similar grooves, and on these grooves more particles appeared. The approximate height of these grooves is $100 \mathrm{~nm}$. By closing up these grooves, some particles of the order of $10 \mathrm{~nm}$ were found in the $X-Y$ plane having an approximate Z-height of $15 \mathrm{~nm}$ (Figure 6).

The results obtained in this work are similar to those that have been reported in the literature [61-64]. Most of these works report morphologies similar to those found in this work, including those we reported in the sample M_14, with the formation of grooves, that was similar to that reported by Jasmin et al. [64], because in an image of phase shows a similar behavior, due 


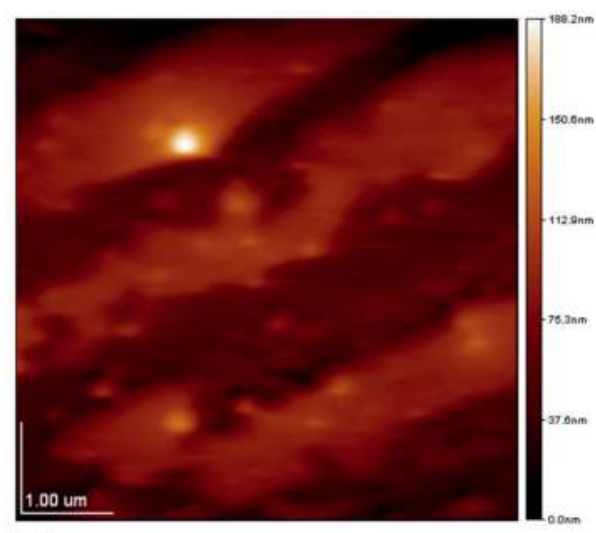

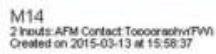
mase ise: $550 \times 550$ in

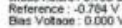
Meaturestov ssom.5000

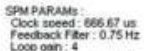

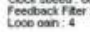

CANTLEVE:

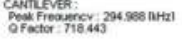
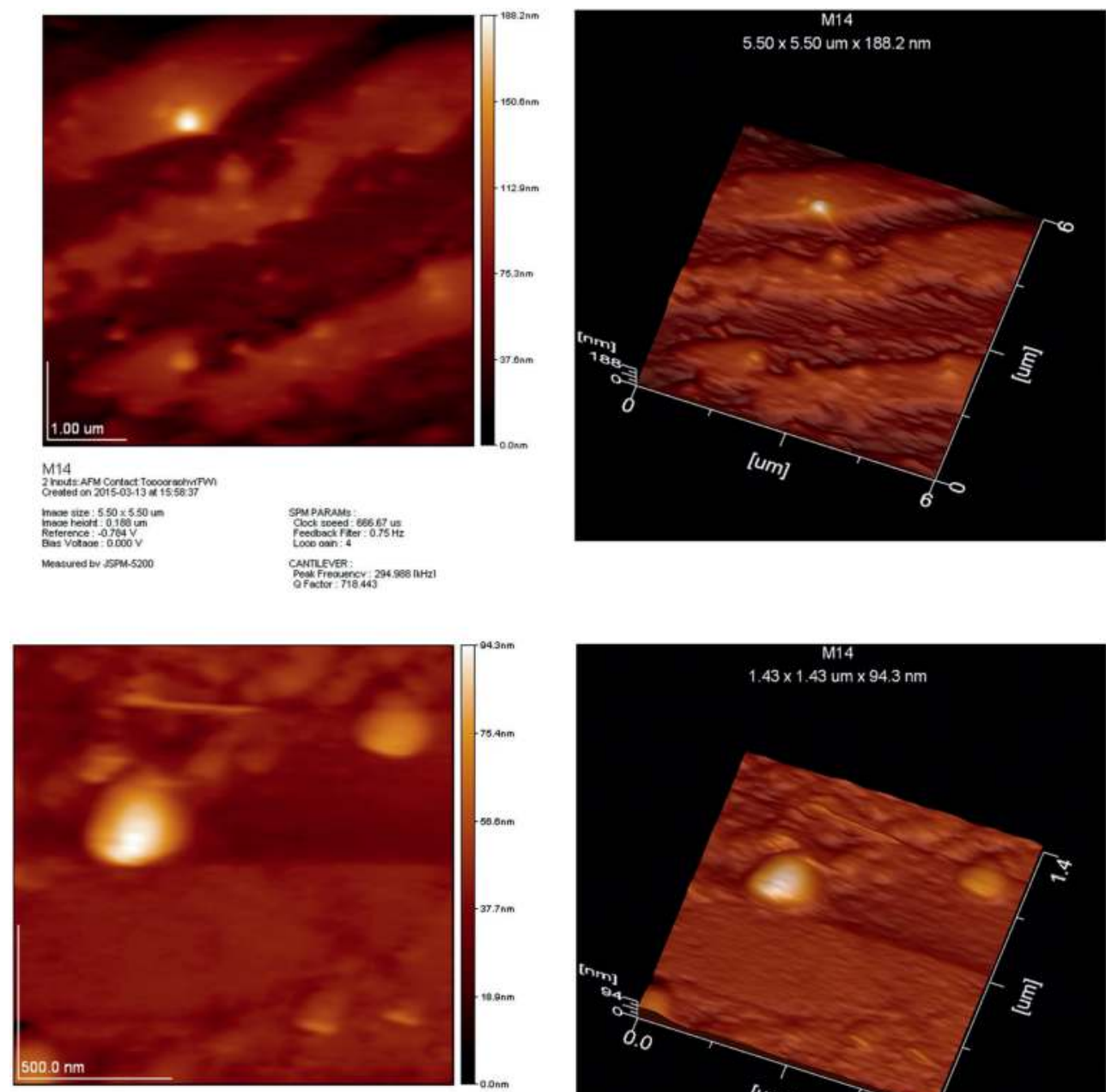

\section{M14}

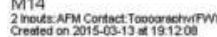

Imas siz: $143 \times 1.43$ um

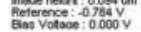

weasured bo sSPM.5200
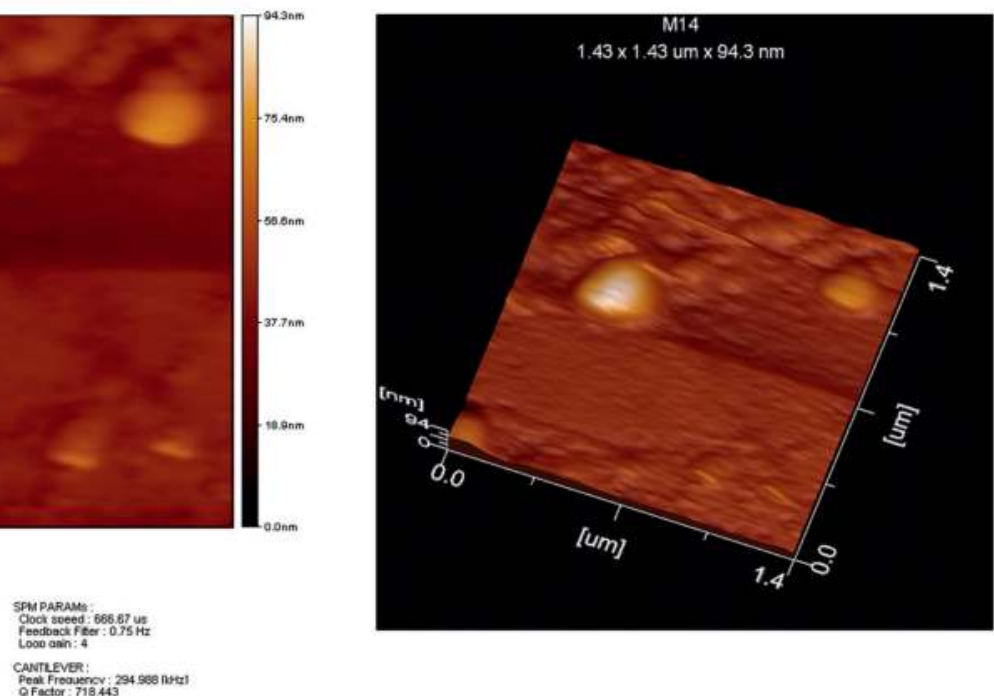

Figure 6. Longitudinal agglomerations, similar grooves, and on these grooves more particles appeared.

to an interference between the sample and the cantilever. However, this behavior is due to the magnetic properties of the particles. Now, in our case, we do not have that kind of properties so we can attribute this behavior to a kind of longitudinal agglomerations of the particles.

\subsection{TEM characterization}

The results of the HRTEM images of the colloidal solutions show the size, shape and preferential orientation of the silicon nanocrystals immersed in the colloidal solution. This 
characterization is presented only for three samples with different solvent (ethanol, methanol and acetone). We could note nanocrystals of different diameter sizes in a range from 1.5 to $8 \mathrm{~nm}$ and different geometrical shapes; some of which were circular, ellipsoidal and some others with not well defined shapes. Ray Mallar et al. [57] also reported nanocrystals of size close to those obtained in the present work $(1.5 \mathrm{~nm})$, with shapes and crystalline orientations similar to the present work.

The three images in Figure 7 correspond to a sample of colloidal solution with acetone solvent; in two of such images, we can notice a large number of spherical and ellipsoidal nanocrystals and other ones similar to agglomerations (irregular shapes); a few more are not clearly perceived because the scale of the image is very large. Possibly the lack of magnification in this image hid the clearer vision of the nanocrystals, although other works have shown areas with spots or black marks as nanocrystals formation [64]. These black marks correspond to the fact that the nanocrystals have been wrapped in an oxide layer. Then, according to what has been reported in the scientific literature, our sample of acetone is immersed with nanometric nanocrystals. We stress that nanocrystals with dimensions larger than $10 \mathrm{~nm}$ were also found. In the image, 6 and $7 \mathrm{~nm}$ nanocrystals were found, and in the inserted images, the diffraction patterns are indicated where crystalline orientations were found to be (220). This result agrees with some orientations that were presented in the X-ray diffractograms. Finally, from the third image, we can identify a black spot; the latter is originated because the thickness of that agglomerate impedes the electrons from penetrating into the sample. Consequently, they are bounced in such a region, forming an image similar to an scanning electron microscopy (SEM) one. However, smaller particles were found, which were detached from this agglomerate; this event is consistent with the AFM images, where there are nanocrystals forming agglomerate (Figure 7) [54].

The second image of Figure 8 corresponds to a colloidal solution with ethanol solvent. It could be noted that only a few dark spots were found. This may be possible because either there exists a smaller amount of nanocrystals or there are a lot of nanocrystals but without the oxidant coating. These nanocrystals were found having an average size between 4 and $5 \mathrm{~nm}$, exhibiting circular shapes and other irregular ones. The inserted images of the diffraction patterns depict preferential crystalline orientations corresponding to (220) and (311). This fact confirms us and at the same time proves that the crystal orientations in X-ray diffraction are similar to those obtained by HRTEM. In relation to the third image of Figure 8, we find that there is agglomerate, but a little thinner, which allows observing the crystallinity of the agglomerate. On the other hand, dark spots were observed here, but the crystal arrangement could be appreciated. This is because the oxide layer is thinner than the crystal. This proves what was mentioned in the acetone images. It leads one to think that core-shell crystals are formed, where the silicon crystals play the role as a core and the oxidizing layer functions as a shell.

The last images corresponding to Figure 9 are attributed to a colloidal solution with methanol solvent, where no dark spots were found. In this case, the resolution scale was far better. It allowed that in this image we could find a larger quantity of nanocrystals with a much smaller size than those found in the previous images, showing sizes from 1.4 to $3.4 \mathrm{~nm}$, with a more circular tendency. In fact, making an approach, it was possible to notice that the whole image was full of nanocrystals with different orientations. In the figures inserted with diffraction patterns, 

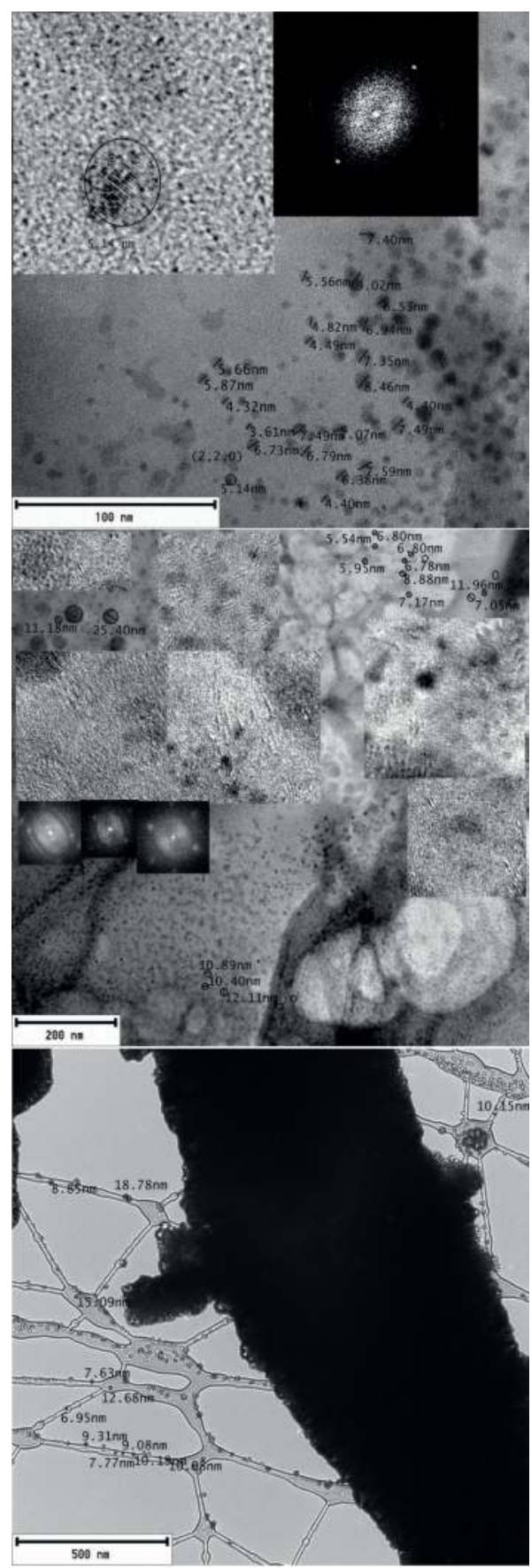

Figure 7. The HRTEM images of colloidal solution with acetone solvent. 

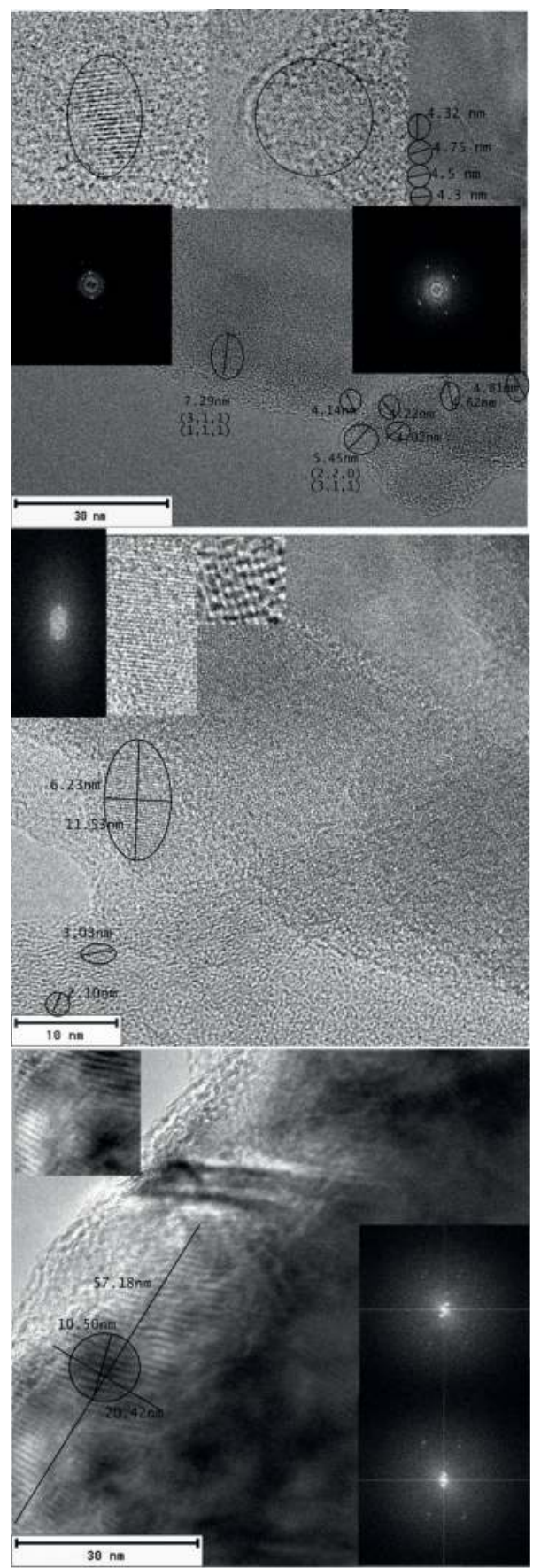

Figure 8. The HRTEM of the colloidal solution with ethanol solvent. 

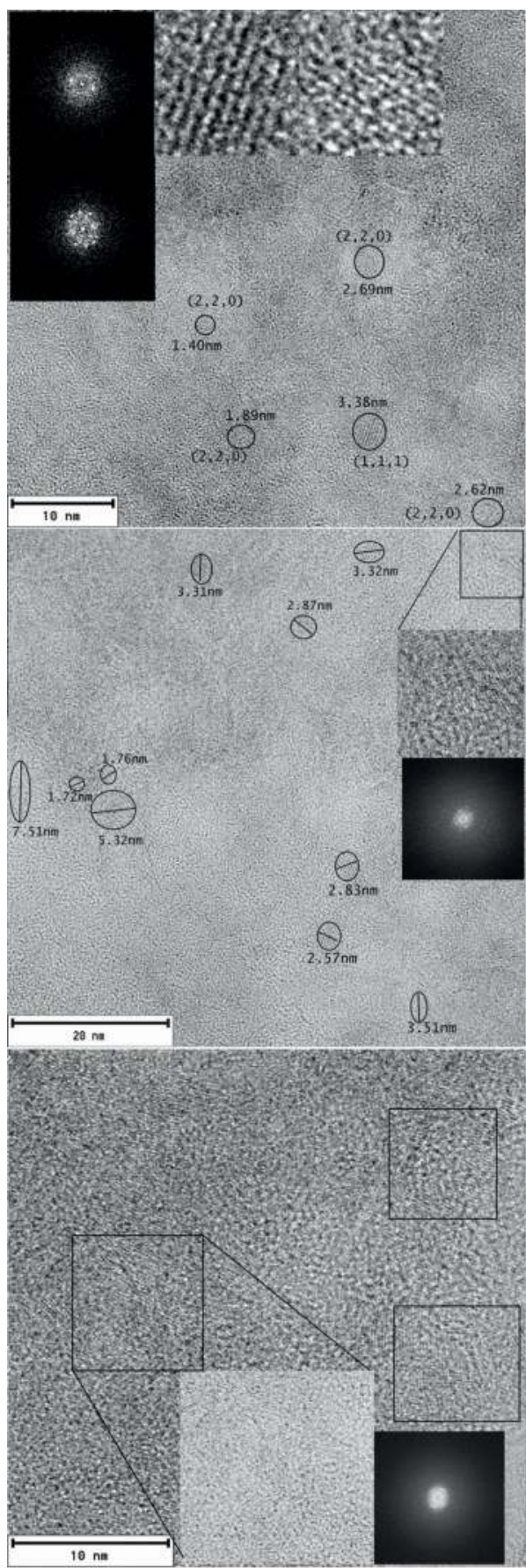

Figure 9. The HRTEM of the colloidal solution with methanol solvent. 
they were found with crystalline preferential orientations of (220) and (111). With this image, we can verify and compare that the results of XRD are similar to those obtained with HRTEM, as well as with the results presented by Mallar et al. [57]. Even in the last image, one can see different regions with nanocrystals shape not well-defined, but with sizes of $1 \mathrm{~nm}$ or less.

The HRTEM images showed the approximate size of the nanocrystals (1.5 nm to $10 \mathrm{~nm}$ ) and a roughly circular shape, Mallar et al. [57] according to their results mention that the HF apparently produces a decrease in the size of the nanocrystals; we can see this in the methanol sample because there are nanocrystals up to $1.4 \mathrm{~nm}$. They also mention that there is a formation of spherical isolated crystals [64]. This is also compatible with our results, since these isolated crystals can be clearly seen in all the samples. According to the diffraction patterns shown in each of the HRTEM figures, some of these image insertions show almost continuous rings. This indicates that there are random orientations of neighboring crystals, that is, a polycrystalline composition. Such presence can also be noticed by diffuse halos which are indicators of an amorphous background that may be due to some type of silicon oxide or even amorphous silicon [57]. According to Mallar et al. [57], HF etching is more effective in the formation of isolated crystals, with regular shapes and nanometric sizes.

We can correlate the size of the nanocrystals with the solvent used. Such fact can be seen in the HRTEM images where the size of the nanocrystals decreased when the solvent was changed. More exactly, for the case of acetone solvent sample, the nanocrystal size was from 7 to $10 \mathrm{~nm}$, with a large number of nanocrystals and core-shell structures. On the other hand, nanocrystal sizes between 4 and $6 \mathrm{~nm}$ were found for the ethanol sample, besides a reduction in the number of nanocrystals and amount of nanocrystals with sizes from 1 to $3 \mathrm{~nm}$ for the methanol sample was found. We attribute this event to the molar mass of each solvent; the molar mass of acetone is $58.08 \mathrm{~g} / \mathrm{mol}$, for ethanol we have a molar mass of $46.06 \mathrm{~g} / \mathrm{mol}$, and for methanol we have a molar mass of $32.02 \mathrm{~g} / \mathrm{mol}$. Due to the differences in the molar masses among the solvents, the formation of nanocrystals and agglomerates is possible.

Figure 10 shows histograms about the distribution of nanocrystals versus diameter. As can be seen, the sample contained in acetone possesses nanocrystals of larger size at $5 \mathrm{~nm}$, while the sample contained in methanol has nanocrystals whose sizes are smaller than $5 \mathrm{~nm}$. Finally, the ethanol sample contains intermediate nanocrystals whose size lies between the two mentioned samples. This can verify in a certain way, the proposed theory, the influence that the solvent has on the size of the nanocrystals.

In the article previously reported by the authors, photoluminescence spectra [54] were shown, which also correlate with PL intensity and nanocrystal size, where acetone samples (M_16 [54]) have a higher PL intensity, but a luminescent emission of longer wavelength; ethanol samples (M_14 [54]) had a lower PL intensity, but with a shift to lower wavelengths and methanol samples (M_09 [54]) had lower PL intensity, but with a higher energy luminescent emission than the previous samples. This can show that the solvent affects the size of the crystals, the luminescent emission and the emission energy. In this case, photoluminescence is affected by quantum confinement and by defects. The emission energy is originated by the nanocrystal size, while the emission intensity is attributed to the presence 

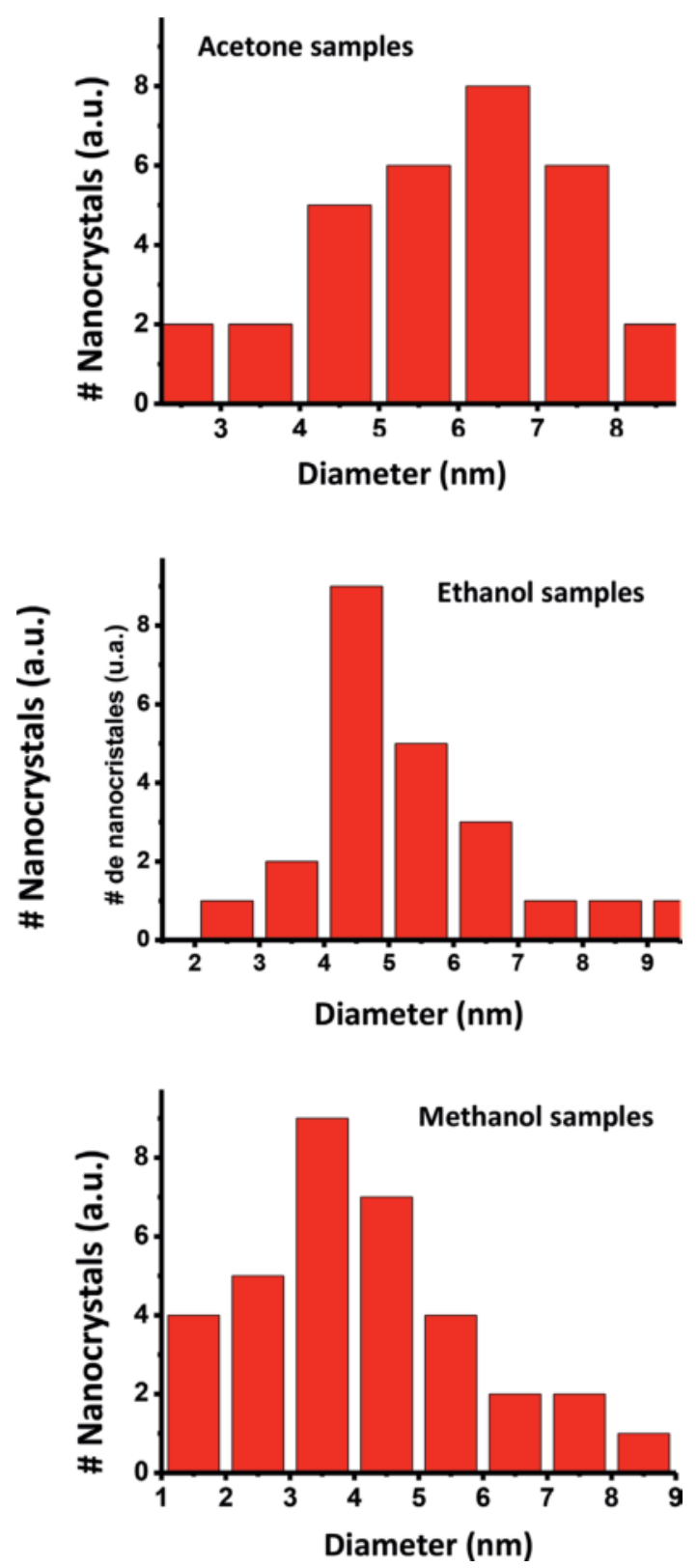

Figure 10. The histograms of the nanocrystals distribution vs. diameter.

of defects which are present in the nanocrystals due to the bonds that are formed with the solvent. From the HRTEM images, it was possible to verify that the different solvents affect the nanocrystal size. 


\section{Conclusions}

We have demonstrated in this work that the synthesis of silicon nanocrystals by means of colloidal solutions is a technique very cheap and so good for controlling the Si-ncs size. By the XRD technique, it was possible to observe the Si-ncs obtained in the colloidal solutions. The AFM images depicted that the colloidal solutions with Si-ncs deposited on silicon have roughness, and it was observed that the Si-ncs possess a process of agglomerations, but it is indubitable that Si-ncs are present. The HRTEM images showed that colloidal solutions with Si-ncs have different agglomerations which exhibit a variable number of such nanocrystals depending on the solvent type. The Si-ncs sizes were possible to obtain in these images, and also, it was possible to observe a clear influence of the solvent type used in the solution. In this study, we were capable of controlling the Si-ncs size without having to use another technique more expensive. Finally, we confirmed the existence of core/shell type particles generated by the oxidated layers formed around the nanocrystal surface, such event may be controllable provided that the appropriate oxidant is selected, in this case the suitable solvent.

\section{Acknowledgements}

This work has been partially supported by CONACyT-255062 and VIEP-BUAP-LULJ EXC2017, PFCE-2017. The authors acknowledge CUVVYT-BUAP laboratory for their help in the measurements of the samples. The authors also want to thank the University of Texas at San Antonio (UTSA) for the HRTEM measurements.

\section{Conflict of interest}

The authors declare that they have no competing interests.

\section{Author details}

Abel Garzón Román ${ }^{1}$, José Alberto Luna López ${ }^{1 *}$, Álvaro David Hernández de la Luz ${ }^{1}$, Estela Gómez Barojas ${ }^{1}$, Alfredo Benítez Lara² ${ }^{2}$ Diana Elizabeth Vázquez Valerdi ${ }^{1}$ and Miguel Ángel Domínguez Jimenez ${ }^{1}$

*Address all correspondence to: jose.luna@correo.buap.mx

1 Semiconductor Device Research Center, IC-CIDS-BUAP, Sciences Institute, Benemeritus Autonomous University of Puebla (Centro de Investigación en Dispositivos Semiconductores, Instituto de Ciencias, Benemérita Universidad Autónoma de Puebla), Edif. IC5 and IC6, Puebla, Puebla, Mexico

2 Catedrático CONACYT, Centro de Investigaciones en Óptica, Colonia Lomas del Campestre León, Guanajuato, México 


\section{References}

[1] Richel A, Johnson NP, McComb DW. Observation of Bragg reflection in photonic crystals synthesized from air spheres in a titania matrix. Applied Physics Letters. 2000;76: 1816-1818. DOI: https://doi.org/10.1063/1.126175

[2] Zacharias M, Heitmann J, Scholz R, Kahler U, Schmidt M, Bläsing J. Size-controlled highly luminescent silicon nanocrystals: $\mathrm{A} \mathrm{SiO} / \mathrm{SiO}_{2}$ superlattice approach. Applied Physics Letters. 2002;80:661

[3] Matsumoto T, Suzuki J, Ohnuma M, Kanemitsu Y, Masumoto Y. Evidence of quantum size effect in nanocrystalline silicon by optical absorption. Physical Review B. 2002; 63:195322

[4] Gardelis S, Nassiopoulou AG, Manousiadis P, Milita S, Gkanatsiou A, Frangis N, Lioutas CB. Structural and optical characterization of two-dimensional arrays of $\mathrm{Si}$ nanocrystals embedded in $\mathrm{SiO}_{2}$ for photovoltaic applications. Applied Physics Letters. 2012;111:083536

[5] Anderson IE, Rebecca A, Shircliff SB, Stradins P, Taylor PC, Collins RT. Synthesis and characterization of PECVD-grown, silane-terminated silicon quantum dots. In: 38th IEEE Photovoltaic Specialists Conference (PVSC). 2012. pp. 001890-001894

[6] Shaji N, Simmons CB, Thalakulam M, Klein LJ, Qin H, Luo H, Savage DE, Lagally MG, Rimberg AJ, Joynt R, Friesen M, Blick RH, Coppersmith SN, Eriksson MA. Spin blockade and lifetime-enhanced transport in a few-electron $\mathrm{Si} / \mathrm{SiGe}$ double quantum dot. Nature Physics. 2008;4:540-544

[7] Nayfeh MH, Rao S, Nayfeh OM, Smith A, Therrien J. UV photodetectors with thin-film Si nanoparticles active medium. IEEE Transactions on Nanotechnology. 2005;4(Suppl 6): 660-668

[8] Zhang J, Liu J, Peng Q, Wang X, Li Y. Nearly monodisperse $\mathrm{Cu}_{2} \mathrm{O}$ and $\mathrm{CuO}$ nanospheres: preparation and applications for sensitive gas sensors. Chemistry of Materials. 2006; 18(Suppl 4):867-871

[9] Kim J, Grate JW. Single-enzyme nanoparticles armored by a nanometer-scale organic/ inorganic network. Nano Letters. 2003;3(Suppl 9):1219-1222

[10] Yang H, Wei W, Liu S. Monodispersed silica nanoparticles as carrier for co-immobilization of bi-enzyme and its application for glucose biosensing. Spectrochimica Acta. Part A, Molecular and Biomolecular Spectroscopy. 2014;125:183-188

[11] Chen HC, Qiu JT, Yang FL, Liu YC, Chen MC, Tsai RY, Yang HW, Lin CY, Lin CC, Wu TS, Tu YM, Xiao MC, Ho CH, Huang CC, Lai CS, Hua MY. Magnetic-composite-modified polycrystalline silicon nanowire field-effect transistor for vascular endothelial growth factor detection and cancer diagnosis. Analytical Chemistry. 2014;86(19):9443-9450

[12] Korzeniowska B, Woolley R, DeCourcey J, Wencel D, Loscher CE, McDonagh C. Intracellular pH-sensing using core/shell silica nanoparticles. Journal of Biomedical Nanotechnology. Jul 2014;10(7):1336-1345 
[13] Deng H, Li X, Peng Q, Wang X, Chen J, Li Y. Monodisperse magnetic single-crystal ferrite microspheres. Angewandte Chemie, International Edition. 2005;44(Suppl 18):2782-2785

[14] Fronthal F, Trifonov T, Rodríguez A, Goyes C, Marsal LF, Borrull JF, Pallarès J. Electrical and optical characterization of porous silicon/p- crystalline silicon heterojunction diodes. AIP Conference Proceedings. 2008;992:780

[15] Izabela J, Filipek K, Duerinckx F, Kerschaver EV, Nieuwenhuysen KV, Beaucarne G, Poortmans J. Chirped porous silicon reflectors for thin-film epitaxial silicon solar cells. Journal of Applied Physics. 2008;104:073529

[16] Tsybeskov L, Duttagupta SP, Hirschman KD, Fauchet PM. Stable and efficient electroluminescence from a porous silicon-based bipolar device. Applied Physics Letters. 1996;68:2058

[17] Peng C, Hirschman KD, Fauchet PM. Carrier transport in porous silicon light-emitting devices. Journal of Applied Physics. 1996;80:295

[18] Perez EX, García FJ, Fenollosa R, Meseguer F. Photonic binding in silicon-colloid microcavities. Physical Review Letters. 2009;103:103902

[19] Tiwari S, Rana F, Chan K, Shi L, Hanafi H. Single charge and confinement effects in nano-crystal memories. Applied Physics Letters. 1996;69(9):1232

[20] Tiwari S, Rana F, Hanafi H, Hartstein A, Crabbe EF, Chan K. A silicon nanocrystals based memory. Applied Physics Letters. 1996;68(10):1377

[21] Nassiopoulou AG. In: Nalwa HS, editor. Encyclopedia of Nanoscience and Nanotechnology. Valencia, CA: American Scientific; 2004;9:793-813

[22] Nassiopoulou AG, Olzierski A, Tsoi E, Salonidou A, Kokonou M, Stoica T, Vescan L. Laterally ordered 2-D arrays of $\mathrm{Si}$ and Ge nanocrystals within $\mathrm{SiO}_{2}$ thin layers for application in non-volatile memories. International Journal of Nanotechnology. 2009;6:18-34

[23] Green MA. Third Generation Photovoltaics: Advanced Solar Energy Conversion. Berlin, Heidelberg: Springer; 2003

[24] Conibeer G. Third-generation photovoltaics. Materials Today. 2007;10(11):42-50

[25] Rölver R, Berghoff B, Batzner D, Spangenberg B, Kurz H, Schmidt M, Stegemann B. Si/ $\mathrm{SiO}_{2}$ multiple quantum wells for all silicon tandem cells: Conductivity and photocurrent measurements Thin Solid Films 2006;516:6763

[26] Cho E-C, Park S, Hao X, Song D, Conibeer G, Park S-C, Green MA. Silicon quantum dot/ crystalline silicon solar cells. Nanotechnology. 2008;19:245201

[27] Ficcadenti M, Pinto N, Morresi L, Murri R, Serenelli L, Tucci M, Falconieri M, Krasilnikova Sytchkova A, Grilli ML, Mittiga A, Izzi M, Pirozzi L, Jadkar SR. Si quantum dots for solar cell fabrication. Materials Science \& Engineering, B: Advanced Functional Solid-State Materials. 2009;66:159-160 
[28] Kim S-K, Cho C-H, Kim B-H, Park S-J, Lee JW. Electrical and optical characteristics of silicon nanocrystal solar cells. Applied Physics Letters. 2009;95:143120

[29] Stupca M, Alsalhi M, Saud TA, Almuhanna A, Nayfeh MH. Enhancement of polycrystalline silicon solar cells using ultrathin films of silicon nanoparticle. Applied Physics Letters. 2007;91:063107

[30] Yuan Z, Pucker G, Marconi A, Sgrignuoli F, Anopchenko A, Jestin Y, Ferrario L, Bellutti P, Pavesi L. Solar Energy Materials \& Solar Cells. 2011;95(4):1224-1227

[31] Green MA, Conibeer G, Cho E-C, Konig D, Huang S, Song D, Scardera G, Cho Y-H, Fangsuwannarak T, Huang Y, Pink E, Bellet D, Bellet Amalric E, Puzzer T. In: 22nd European Photovoltaic Solar Energy Conference (Milan, Italy); 2007. pp. 1-4

[32] Igarashi M, Budiman MF, Pan W, Weiguo H, Tamura Y, Syazwan ME, Usami N, Samukawa S. Effects of formation of mini-bands in two-dimensional array of silicon nanodisks with $\mathrm{SiC}$ interlayer for quantum dot solar cells. Nanotechnology. 2013;24:015301

[33] Rodriguez I, Fenollosa R, Meseguer F. Silicon microspheres as UV, visible and infrared filters for cosmetics. Cosmetic \& Toiletries. 2010;125(9):42-50

[34] Levitsky IA, Euler WB, Tokranova N, Rose A. Fluorescent polymer-porous silicon microcavity devices for explosive detection. Applied Physics Letters. 2007;90:041904

[35] Zhou Z, Brus L, Friesner R. Electronic structure and luminescence of 1.1- and 1.4-nm silicon nanocrystals: Oxide shell versus hydrogen passivation. Nano Letters. 2003;3:163-167

[36] Fojtik A, Henglein A. Luminescent colloidal silicon particles. Chemical Physics Letters. 1994;221:363-367

[37] Chen XY, Lu YF, Wu YH, Cho BJ, Liu MH, Dai DY, Song WD. Mechanisms of photoluminescence from silicon nanocrystals formed by pulsed-laser deposition in argon and oxygen ambient. Journal of Applied Physics. 2003;93:6311

[38] Vanhellemont J, De Gryse O, Clauws P. Critical precipitate size revisited and implications for oxygen precipitation in silicon. Journal of Applied Physics. 2005;86:221903

[39] Shimizu-Iwayama T, Fujita K, Nakao S, Saitoh K, Fujita T, Itoh N. Visible photoluminescence in Si+-implanted silica glass. Journal of Applied Physics. 1994;75:7779-7783

[40] Min KS, Shcheglov KV, Yang CM, Atwater HA, Brongersma ML, Polman A. Defectrelated versus excitonic visible light emission from ion beam synthesized Si nanocrystals in $\mathrm{SiO}_{2}$. Applied Physics Letters. 1996;69:2033-2035

[41] Littau KA, Szajowski PJ, Muller AJ, Kortan AR, Brus LE. A luminescent silicon nanocrystal colloid via a high-temperature aerosol reaction. The Journal of Physical Chemistry. 1993;97:1224-1230

[42] Holunga DM, Flagan RC, Atwater HA. A scalable turbulent mixing aerosol reactor for oxide-coated silicon nanoparticles. Industrial \& Engineering Chemistry Research. 2005; 44:6332-6341 
[43] Zhang Q, Bayliss SC, Hutt DA. Blue photoluminescence and local structure of Si nanostructures embedded in $\mathrm{SiO}_{2}$ matrices. Applied Physics Letters. 1995;66:1977-1979

[44] Schmidt JU, Schmidt B. Investigation of Si nanocluster formation in sputter-deposited silicon sub-oxides for nanocluster memory structures. Materials Science and Engineering B. $2003 ; 101: 28-33$

[45] Lin CF, TsengW T, Feng MSJ. Formation and characteristics of silicon nanocrystals in plasma-enhanced chemical vapor-deposition silicon-rich oxide. Applied Physics. 2000; 87:2808-2815

[46] Nozaki T, Sasaki K, Ogino T, Asahi D, Okazaki K. Microplasma synthesis of tunable photoluminescent silicon nanocrystals. Nanotechnology. 2007;18:235603

[47] Saunders WA, Sercel PC, Lee RB, Atwater H, Vahala KJ, Flanagan RC, Escorsi-Aparcio EJ. Synthesis of luminescent silicon clusters by spark ablation. Applied Physics Letters. 1993;63:1549-1551

[48] Kahler U, Hofmeister H. Visible light emission from Si nanocrystalline composites via reactive evaporation of SiO. Optical Materials. 2001;17:83-86

[49] Lin CF, TsengW T, Feng MS. Formation and characteristics of silicon nanocrystals in plasma-enhanced chemical-vapor-deposited silicon-rich oxide. Journal of Applied Physics. 2000;87:2808-2815

[50] Nozaki T, Sasaki K, Ogino T, Asahi D, Okazaki K. Microplasma synthesis of tunable photoluminescent silicon nanocrystals. Nanotechnology. 2007;18:235603

[51] Lioutas C, Vouroutzis N, Tsiaoussis I, Frangis N, Gardelis S, Nassiopoulou AG. Columnar growth of ultra-thin nanocrystalline Si films on quartz by low pressure chemical vapor deposition: accurate control of vertical size. Physica Status Solidi A: Applications and Materials Science. 2008;205:2615

[52] Shimizu-Iwayama T, Fujita K, Nakao S, Saitoh K, Fujita T, Itoh N. Visible photoluminescence in Si+-implanted silica glass. Journal of Applied Physics. 1994;75:7779-7783

[53] Min KS, Shcheglov KV, Yang CM, Atwater HA, BrongersmaM L, Polman A. Defectrelated versus excitonic visible light emission from ion beam synthesized Si nanocrystals in $\mathrm{SiO}_{2}$. Applied Physics Letters. 1996;69:2033-2035

[54] López JAL, Román AG, Barojas EG, Flores Gracia JF, Juárez JM, López JC. Synthesis of colloidal solutions with silicon nanocrystals from porous silicon. Nanoscale Research Letters. 2014;9:571

[55] Morris MC, McMurdie HF, Evans EH, Paretzkin B, de Groot JH, Hubbard CR, Carmet SJ, Standard X-ray Diffraction Powders Ptterns, 1976; section 13:44:25/sec 12:35

[56] Han PG, Poon MC, Sin KO, Wong M. Photoluminescent porous polycrystalline silicon. In Electron Devices Meeting, Proceedings IEEE Hong Kong. 1995:2-5 
[57] Ray M, Hossain SM, Klie RF, Banerjee K, Ghosh S. Free standing luminescent silicon quantum dots: evidence of quantum confinement and defect related transitions. Nanotechnology. 2010;21(Suppl 50):9

[58] Zang JB, Wang YH, Zhao SZ, Bian LY, Lu J. Electrochemical properties of nanodiamond powder electrodes. Diamond and Related Materials. 2007;16:16-20

[59] He D, Shao L, Gong W, Xie E, Xu K, Chen G. Electron transport and electron field emission of nanodiamond synthesized by explosive detonation. Diamond and Related Materials. 2000;9:1600-1603

[60] Yerci S, Serincan U, Dogan I, Tokay S, Genisel M, Aydinli A, Turan R. Formation of silicon nanocrystals in sapphire by ion implantation and the origin of visible photoluminescence. Journal of Applied Physics. 2006;100:074301

[61] Boer EA, Brongersma ML, Atwater HA, Flagan RC, Bell LD. Localized charge injection in $\mathrm{SiO}_{2}$ films containing silicon nanocrystals. Applied Physics Letters. 2001;79:791

[62] Maqbool M, Ali G, Cho SO, Ahmad I, Mehmood M, Kordesch ME. Nanocrystals formation and intense green emission in thermally annealed AlN:Ho films for microlaser cavities and photonic applications. Journal of Applied Physics. 2010;108:043528

[63] Cahay M, Garre K, Wu X, Poitras D, Lockwood DJ, Fairchild S. Physical properties of lanthanum monosulfide thin films grown on (100) silicon substrates. Journal of Applied Physics. 2006;99:123502

[64] Jasmin A, Rillera H, Semblante O, and Sarmago R. Surface morphology, microstructure, Raman characterization and magnetic ordering of oxidized Fe-sputtered films on silicon substrate. AIP Conference Proceedings. 2012;1482:572 
